\title{
Effects of STEAMification Model in Flipped Classroom Learning Environment on Creative Thinking and Creative Innovation
}

\author{
Naphong Wannapiroon, Sirirat Petsangsri \\ King Mongkut's Institute of Technology Ladkrabang, Bangkok, Thailand
}

\begin{abstract}
This paper is a report on the findings from the research and development of STEAMification model in flipped classroom learning environment to enhance creative thinking and creative innovation. The purposes of this study are: 1) to develop the model; 2) to study the developed model.

Results exhibited that: 1) the model consists of 6 components, 2) the students who had studied through STEAMification had higher creativity $($ Mean $=14.53$, S.D. $=0.94)$ than the students who studied through normal model $($ Mean $=12.90$, S.D. $=1.91)$, 3) the students who had studied through model had higher quality of creative innovation $($ Mean $=14.86$, S.D. $=$ 1.62) than the students who studied through normal model $($ Mean $=12.90$, S.D. $=1.91)$.
\end{abstract}

Keywords - Virtual Learning Ecosystem, STEAMification, STEAM education, Gamification, Digital Leaning, Creative Thinking, Creative Innovation.

\section{Introduction}

Stepping from the industrial revolution to the digital age resulted in a demand for the labor market changes. Skills that are repeated are not enough anymore since computers can do this instead.

DOI: 10.18421/TEM94-42

https://doi.org/10.18421/TEM94-42

Corresponding author: Naphong Wannapiroon, King Mongkut's Institute of Technology Ladkrabang, Bangkok, Thailand.

Email: naphong.w@rmutsb.ac.th

Received: 13 April 2020.

Revised: 17 September 2020.

Accepted: 24 September 2020.

Published: 27 November 2020.

(c) BY-NC-ND (C) 2020 Naphong Wannapiroon \& Sirirat Petsangsri; published by UIKTEN. This work is licensed under the Creative Commons AttributionNonCommercial-NoDerivs 4.0 License.

The article is published with Open Access at www.temjournal.com
Skills that will play an important role in the $21^{\text {st }}$ century are social \& emotional skills, and the demand for careers with these skills is increasing. In the past years, the world economic forum has defined 16 skills for the $21^{\text {st }}$ century, divided into 3 categories namely life skill to suit the context of today's world, management skill for life challenging, and coping skill with a rapidly changing world. The processes used to build these skills cannot be created from traditional classroom processes. Gamification \& game-based learning, simulation game, and coach \& facilitator are one of the processes that help to develop skills for the $21^{\text {st }}$ century, especially in social \& emotional skill, in line with the flipped classroom, which is a learning approach that focuses on organizing teaching and learning activities by creating learning environment and atmosphere. Teaching approach for the instructor learning styles of the learner, teaching media, communication channel, and the interaction model between learners and instructors, learners and learners, learners and learning content, learners various learning contexts, and organize teaching and learning activities focus on flexibility to respond to individual differences of learners, so that each learner gets the best results from the course [1].

The development of education in the $21^{\text {st }}$ century through flipped classroom begins with training the learners for self-learning, such as how to watch video clips, gathering ideas, innovative thinking, concentrative, informative, and repeat if needed. The learners practice how to write notes, write mind maps, set interesting questions and prepare to ask instructor. Instructors change roles from instructor to mentors, coaches, or learning facilitators. The instructors need to have real knowledge, ready to learn new things, knowledge organization, knowledge management, and to able to create motivation for learners. The instructor needs to change learning environment by creating a learning atmosphere, in which the learners direct their own learning. Report or oral presentation may be presented as digital storytelling. The instructors invite students to reflect what they have learned, 
what else they want to know and why, and develop thinking about ethical values. Integrated learning in interdisciplinary studies, linking knowledge with imagination and transforming into concrete issue with the skills needed in the $21^{\text {st }}$ century, such as working together to establish creativity, problemsolving and effective communication. Education has to satisfy the learners and challenge the learning process, inquire to study and have fun through gamification for education [2].

As far as education in the digital age is concerned, learners need to know the right way to learn and have more growth mindset. Instructors have to change the role from lecturer to facilitator. Educational institutions and courses need to adapt and provide opportunities for new teaching and learning approach, which will suit the needs of the changing learners. STEAM Education is an educational approach that integrates science, technology, engineering, art, and mathematics in order to provide learners with creative skill, investigation skill, debate skill, critical thinking skill, and creativity and innovation [3]. The result is that learners have thinking skill, participate in learning experiences as well as problem solving, collaboration, and the use of creative thinking processes at work [4]. These characteristics will appear in innovators, educators, leaders and desirable characteristics of learners in the $21^{\text {st }}$ century.

From the background and importance mentioned above, it is necessary to develop the STEAMification Model in Flipped Classroom Learning Environment to enhance students' creative skills and creative innovation, which are desirable characteristics of learners in the $21^{\text {st }}$ century.

\section{Research Objectives}

2.1. Develop the STEAMification model in flipped classroom learning environment to enhance creative thinking and creative innovation.

2.2. Compare the creative scores and the quality scores of creative innovation of students studying through STEAMification model in flipped classroom learning environment with the control group students studying through traditional approach.

\section{Theoretical Foundations}

\subsection{Flipped Classroom Ecosystem}

The flipped classroom learning environment is a learning management method for an online learning environment through a collaborative cloud together with organizing meaningful learning activities in an open-faced classroom [5]. The virtual learning ecosystem consists of 4 concepts: flexible environment, changing teaching and learning styles to meaningful learning, which changes learners to think critically. The learners intend to study the content on their own, and the instructors transform their role to be a learning facilitator by encouraging learners to learn in a traditional classroom learning environment and self-study through an online learning environment in order to encourage the learners to learn mastery. The tools used to create flipped classroom learning environment is a collaborative cloud learning and cloud learning management system [6].

\subsection{Collaborative Cloud Learning}

Collaborative cloud learning refers to using cloud technology service in the form of software as a service for learning and working together in flipped classroom learning environment, and it consists of 5 major modules as follow: [7],[8],[9];

- Publishing Cloud: is using blog-based platforms and multimedia distribution platforms, such as web blogs and social cloud networks

- Sharing Cloud: is using platforms for video sharing or live streaming, platforms for sharing documents, and platforms for sharing image data.

- Meeting Cloud: is using a platform that supports networking meetings, including the ability to send and receive data or other resources within a discussion group.

- Discussing Cloud: is using the platform for sending and receiving emails or short messages, and a platform for private and group conversations for e-brainstorming.

- Collaborating Cloud: is using a platform for time synchronization collaboration and non-time synchronization via cloud.

\subsection{STEAM Education}

STEAM Education refers to a teaching and a learning style that integrates the principles of 5 sciences namely science, technology, mathematics, art and engineering for students to apply all fields of knowledge in problem solving and innovation. It consists of 5 steps of learning process as follows: [10], [11], [12];

- Investigating step is a process of asking questions, selecting topics from the source of problems in accordance with the answers wanted.

- Discovery step is a process of planning or creating a pattern for selected topics or questions to see trends in surveys.

- Connecting step is a process of connecting various sciences together for learning and innovation. 
- Creating step is a process of developing innovation from knowledge from various sciences as planned.

- Reflecting step is a process for students to reflect on the results of what they can learn.

\subsection{Gamification}

Gamification means a learning environment in which game mechanics are used to stimulate or promote collaborative learning processes in a context in which learners learn or work together through information technology in a flipped classroom learning environment. It consists of 3 components as follows: [10], [13],[14]

1) Game Mechanics means the main structure of the game, and it consists of playing methods, rules, and a reward. The purpose of playing game or various interactive methods that respond to the feeling of playing the game, both the perspective of challenges, fun, satisfaction, or other emotional responses which instructors want to give to the learners are such as:

1.1) Defining goals to create challenges for successful activities;

1.2) Collecting point to receive prizes in which the forms vary according to the objectives;

1.3) Promoting level to shows the level of the user which can be increased with participation. When the level is higher users will receive different special privileges.

1.4) Badges logo is a mechanism created to represent various missions. When the mission is completed users will receive rewards. The main objective is to create engagement and try to keep users engaged with the system as long as possible.

1.5) Leaderboards is to show the user's position. The purpose is to create competition on the platform.

2) Game Dynamics refers to the behavior or reaction of the learners that is driven by the use of game mechanics namely:

2.1) Award - the need of receiving reward when the learners are successful in the activity in each step;
2.2) Achievement - the need to gain achievement when students are able to complete the specified activities;

2.3) Challenge - the motivation for learners to desire to participate in activities;

2.4) Competition - the challenge of competing with others;

3) Emotions mean the feelings of each learner while conducting gamification learning activities as the instructor has defined. It is a result of game mechanics and responsiveness to game dynamics.

\subsection{Creative Thinking Skill}

Creative Thinking Skill is the score obtained from the evaluation of creative skill developed from the Guilford's concept (1991). It consists of 4 sub-skills namely originality thinking, fluency thinking, flexibility thinking, and elaborate thinking [15].

\subsection{Creative Innovation}

Creative innovation means score obtained from evaluation of students' creative innovation after learning through STEAMification model in flipped classroom learning environment in order to enhance creativity and creative innovation of the undergraduate students. The model is developed with new product evaluation criteria or better. It consists of 5 components namely novelty and uniqueness, objective, efficiency, possibility of usage, and cost value.

\section{Research Scope}

\section{Population and Samples}

4.1. The population used in the research was undergraduate students of Multimedia Technology Program, Faculty of Science and Technology;

4.2. Samples used in the research were year 3 undergraduate students of Multimedia Technology Program, Faculty of Science and Technology in Semester 2, Academic Year 2019. The samples included 2 study groups, 60 students, and they were divided into an experimental group of 60 students and a control group of 30 students. The samples were obtained by random sampling. 


\section{Research Framework}

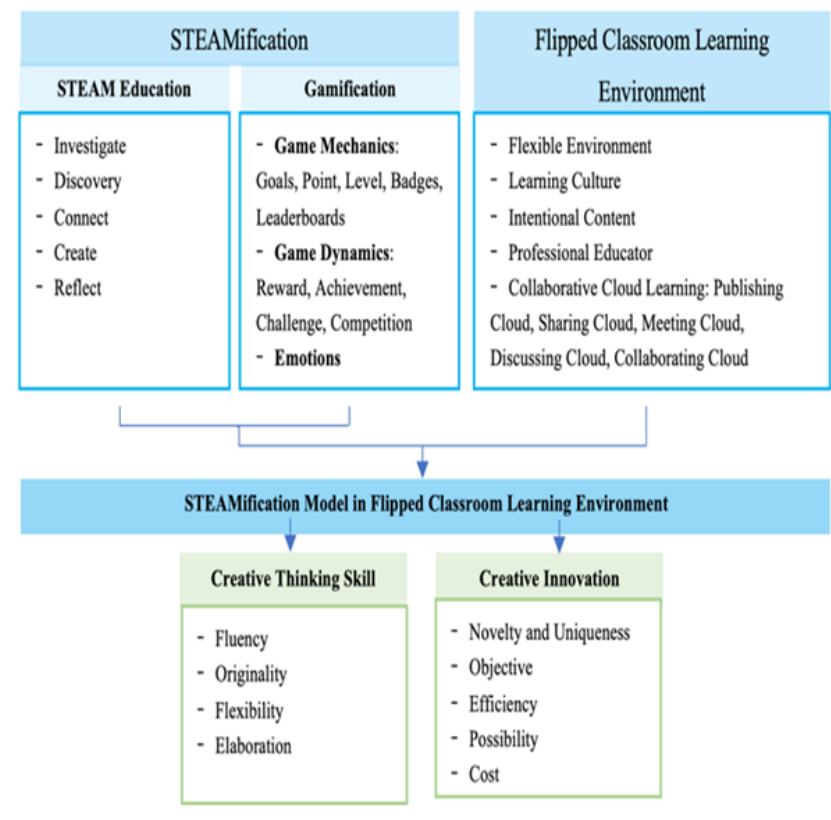

Figure 1. The Research Framework

\section{Research Methodology}

The research methodology is divided into 3 steps according to the research objectives as follows.

\subsection{Development of the STEAMification model in flipped classroom learning environment to enhance creative thinking and creative innovation proceeded as follows:}

6.1.1. Created a STEAMification process in flipped classroom learning environment by studying the synthesis of documents and research related to STEAM Education, Gamification, Collaborative Cloud Tools, and Flipped Classroom. The instruments used in this research were content Analysis form. The data were synthesized by content analysis, and evaluated for the suitability of STEAMification process.

6.1.2. Development of the STEAMification model in flipped classroom learning environment to enhance creative thinking and creative innovation comprises:

6.1.2.1. Analysis is learner Analysis, Content Analysis and Context Analysis.

6.1.2.2. Design is to specify the learning objectives, Design Learning Strategy and Design Measurement and Evaluation.

6.1.2.3. Development is the development of STEAMification model in flipped classroom learning environment to enhance creative thinking and creative innovation, develop the plan for teaching and learning activities, and it creates quality instruments used to study the results of the study by using the STEAMification learning model namely the evaluation form of creative skills, creative innovation, and satisfaction evaluation form.

6.1.2.4. Evaluation is a method to critiques and evaluates the suitability of the learning model, and teaching and learning activities plan. The instruments used in the study of research findings were focus groups of 10 experts. The experts were purposively selected for those that have at least 5 years of relevant experience. The instruments used in this study were the evaluation form, by which the suitability of the learning model can be certified. Data were analyzed by using content analysis, arithmetic mean and standard deviation.

\subsection{Studying learning result of the STEAMification model in flipped classroom learning environment proceeded according to experimental group and control group design as follows:}

$\begin{array}{llll}\text { Experimental group (E) } & O_{1 \mathrm{E}} & \mathbf{X} & \mathbf{O}_{2 \mathrm{E}} \\ \text { Control Group (C) } & \mathbf{O}_{1 \mathrm{C}} & -- & \mathbf{O}_{2 \mathrm{C}}\end{array}$

6.2.1. Preparation before the experiment comprises: preparation of the computer laboratory, orientation, guide learning activities, practice using the STEAMification Learning Management System (STG-LMS), measuring and evaluation of creative skills before learning.

6.2.2. Learning Activity: Conduct experiments using the developed STEAMification Learning Model with the year 3 undergraduate students of Multimedia Technology Program, Faculty of Science and Technology in Semester 2, Academic Year 2019. The samples included 2 study groups, 60 students who were divided into an experimental group of 60 students and a control group of 30 students. The samples were obtained by random sampling.

6.2.3. Comparison of creative scores of the students studying through the STEAMification Model in Flipped Classroom Learning Environment and the control group students studying through traditional approach was carried out. The research instruments were the creative evaluation form with ItemObjective Congruence Index (IOC) between 0.86 1.00. The statistics used in data analysis was t-test independent.

6.2.4. Comparison of quality score of the creative innovation of students studying through the STEAMification Model in Flipped Classroom Learning Environment and the control group students studying through traditional approach was carried out. The research instruments were the quality evaluation form of creative innovation with IOC between 0.71 - 1.00. The statistics used in data analysis was t-test independent. 


\section{Research Results}

\subsection{STEAMification Model in Flipped Classroom Learning Environment to enhance creative thinking and creative innovation}

7.1.1. The component of the STEAMification in flipped classroom learning environment consists of 6 major components namely instructor, learner, learning content, online resource, infrastructure, and flipped classroom learning environment.

The components of the STEAMification are as presented in Figure 2.

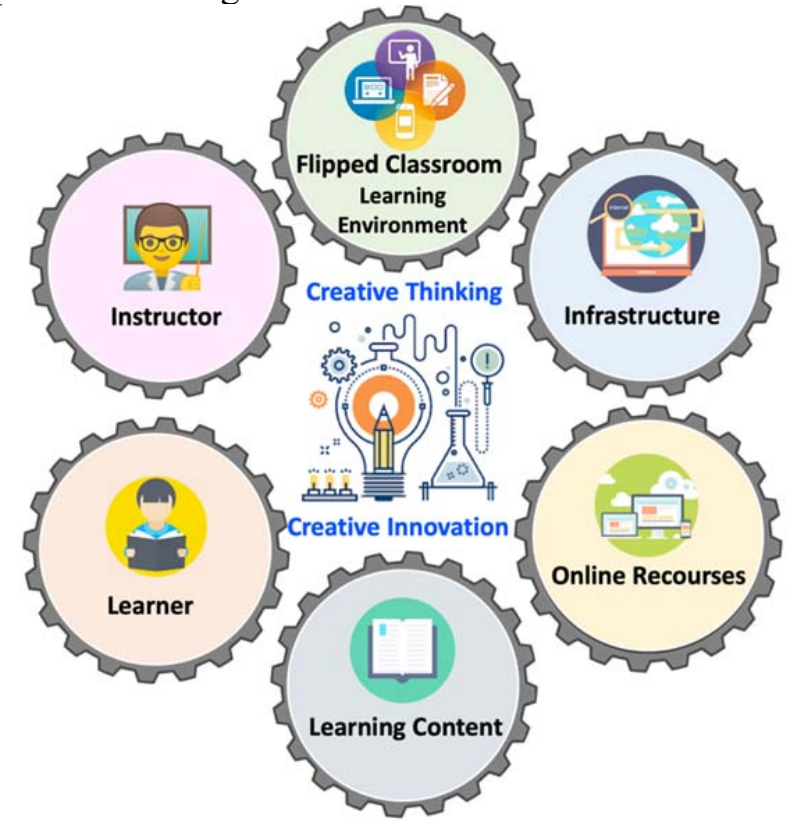

Figure 2. The component of the STEAMification

7.1.2. The learning process of STEAMification in flipped classroom learning environment to enhance creative thinking and creative innovation.

The learning process of STEAMification in flipped classroom learning environment to enhance creative thinking and creative innovation consists of 3 majors steps as follows:

\subsubsection{Preparation before the Experiment:}

- Learners orientation, in which the instructor informs about learning objectives, how to learn through STEAMification LMS, self-leading learning, self-monitoring, how to measure and evaluate.

- Practice how to use technology enhances learning such as collaborative cloud learning, cloud learning management, and information searching tools.

7.1.2.2. STEAMification learning activity in Flipped Classroom Learning Environment:
- Organizing the STEAMification learning activity is a learning management base on STEAMification. It is STEAM education using game mechanics and game dynamics consists of 5 steps as follows:

1) Investigate - Using the game mechanism namely setting goals, accumulating points, badges, and leader boards. Using game dynamics namely desire when one wants to be rewarded, which also includes desire to accomplish the mission, and desire for a challenging.

2) Discovery - Using game mechanics namely setting goals, accumulating points, badges, leader boards, and promotion. Using game dynamics namely desire when one wants to be rewarded, which also includes desire to accomplish the mission, desire for a challenging, and desire for competition.

3) Connect - Using game mechanics namely setting goals, accumulating points, badges, leader boards, and promotion. Using game dynamics namely desire when one wants to be rewarded, including desire to accomplish the mission, desire for a challenging, and desire for competition.

4) Create Creative Innovation - The learners jointly develop creative innovation from the integration of various sciences such as science, technology, engineering, art and mathematics. Using game mechanics namely setting goals, accumulating points, badges, leader boards, and promotion. Using game dynamics namely desire when one wants to be rewarded, which also includes desire to accomplish the mission, desire for a challenging, and desire for competition.

5) Reflect - Using game mechanics namely setting goals, accumulating points, badges, leader boards, and promotion. Using game dynamics namely desire when one wants to be rewarded, including desire to accomplish the mission, desire for a challenging, and desire for competition.

\subsubsection{Evaluation}

Evaluation of students' learning according to the STEAMification Model in Flipped Classroom Learning Environment consists of 2 aspects:

- Creative Thinking Skill, which consists of 4 subskills namely originality, fluency, flexibility and elaboration thinking. The evaluation instrument was the creative skills evaluation form based on rubric valuated by 3 experts.

- Creative Innovation consists of 5 components namely Novelty and Uniqueness, Objective Problem Solving, Efficiency, Possibility, Cost. The evaluation instrument was the creative innovation evaluation form based on rubric valuated by 3 experts. 


\section{Flipped Classroom Learning Environment}

Flipped classroom learning environment consists of concrete environment through game mechanics namely goal setting, score accumulation, achievements, leader boards, and promotion. These are for face-to-face learning in the classroom. The abstract environment comprises the game dynamics namely desire to be rewarded, desire to accomplish the mission, desire for a challenging, and desire for competition. These are for online learning outside the classroom.

The learning process of the STEAMification model in flipped classroom learning environment consists of investigate, discovery, connect, create, and reflect items. The gamification consists of 2 major components namely game mechanics, which consists of goal, point, level, badges, and leaderboard. The game dynamic consists of reward, achievement, challenge, and competition. The flipped classroom learning environment consists of concrete environment, which is made by game mechanics for face-to-face learning in classroom. Abstract environment is organized by game dynamics for learning online outside classroom.

Learning support technologies include collaborative cloud learning in the form of Software as a Service,

sharing cloud, meeting cloud, discussing cloud, and collaborating cloud. The STEAMification model in flipped classroom learning environment (STEAMLMS) consists of badges, leaderboards, web board, online assignment, weblog, online mind map, online scaffolding.

The processes of STEAMification in flipped classroom learning environment are as presented in Figure 3.

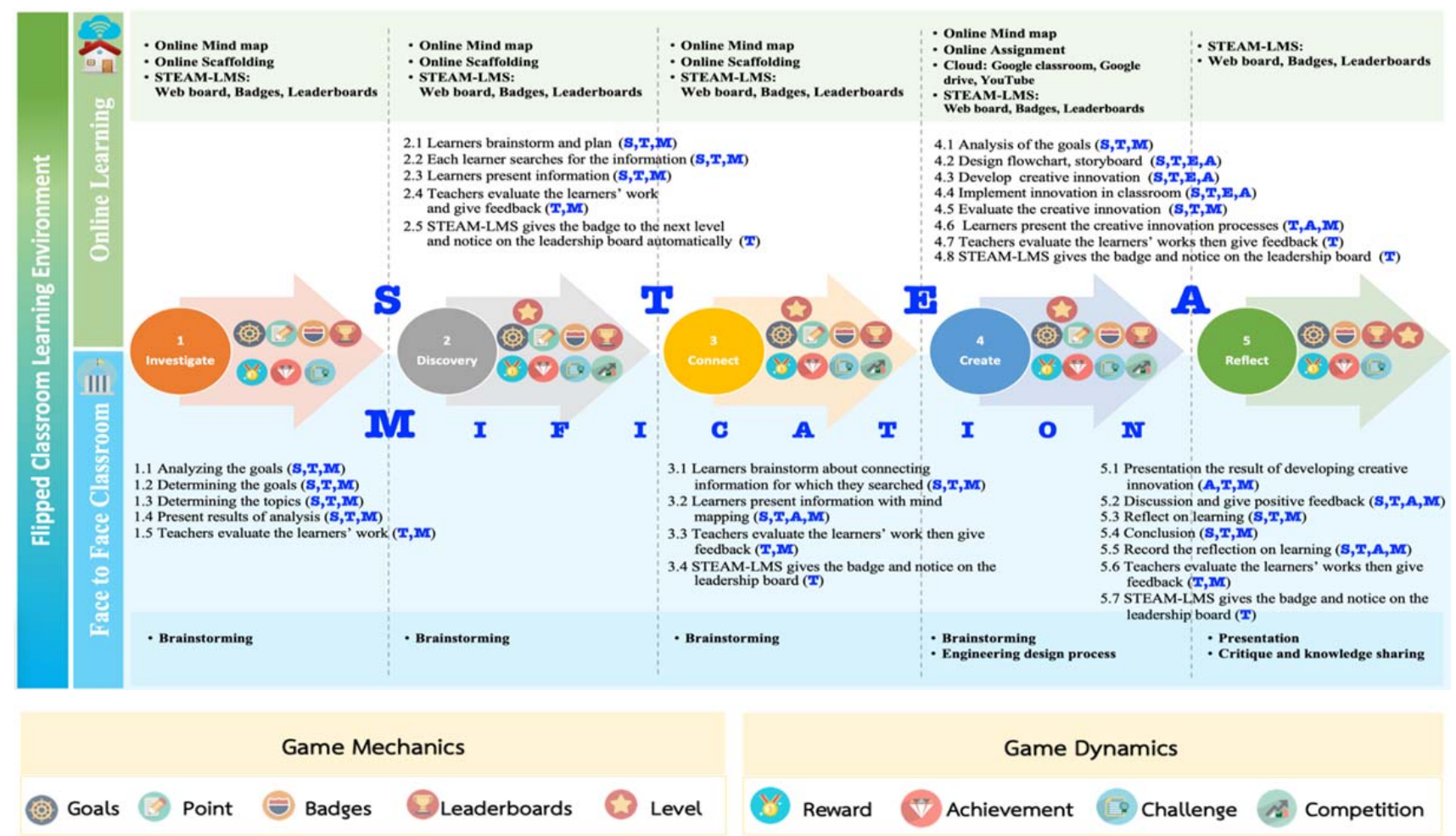

Figure 3. The STEAMification process in flipped classroom learning environment 
The STEAMification model in flipped classroom learning environment is presented in Figure 4 as follows:

\section{Flipped Classroom Learning Environment}

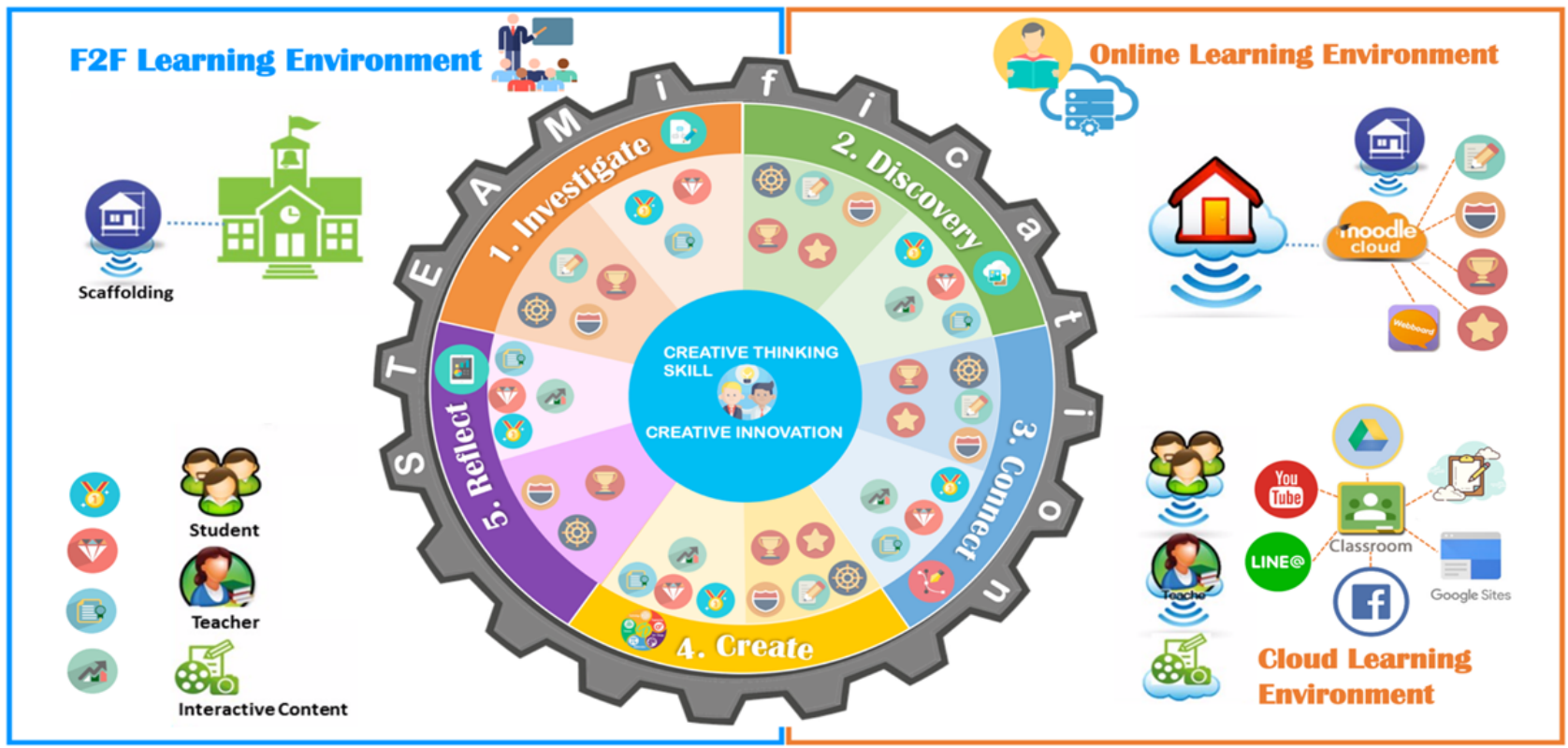

Figure 4. The STEAMification model in flipped classroom learning environment

Table 1. The suitability evaluation result of the components of the STEAMification model in flipped classroom learning environment $(n=17)$

\begin{tabular}{lccc}
\hline \multicolumn{1}{c}{ Evaluation Items } & Mean & S.D. & Suitability \\
\hline Instructor & 4.88 & 0.33 & Highest \\
\hline Learner & 4.82 & 0.39 & Highest \\
\hline Learning Content & 4.94 & 0.24 & Highest \\
\hline Online Recourses & 4.82 & 0.39 & Highest \\
\hline Infrastructure & 4.94 & 0.24 & Highest \\
\hline $\begin{array}{l}\text { Flipped Classroom } \\
\text { Learning Environment }\end{array}$ & 4.76 & 0.44 & Highest \\
\hline \multicolumn{1}{c}{ Total } & $\mathbf{4 . 8 6}$ & $\mathbf{0 . 3 5}$ & Highest \\
\hline
\end{tabular}

Table 2. The suitability evaluation result of the STEAMification processes $(n=17)$

\begin{tabular}{|c|c|c|c|}
\hline Evaluation Items & Mean & S.D. & Suitability \\
\hline $\begin{array}{l}\text { Preparation before } \\
\text { learning }\end{array}$ & 4.82 & 0.39 & Highest \\
\hline \multicolumn{4}{|c|}{$\begin{array}{l}\text { Organizing learning activities through the } \\
\text { STEAMification }\end{array}$} \\
\hline Investigate & 4.76 & 0.44 & Highest \\
\hline Discovery & 4.47 & 0.80 & High \\
\hline Connect & 4.65 & 0.61 & Highest \\
\hline $\begin{array}{l}\text { Create Creative } \\
\text { Innovation }\end{array}$ & 4.76 & 0.44 & Highest \\
\hline Reflect & 4.53 & 0.72 & Highest \\
\hline \multicolumn{4}{|l|}{ Evaluation } \\
\hline Creative Thinking Skill & 4.76 & 0.44 & Highest \\
\hline Creative Innovation & 4.53 & 0.62 & Highest \\
\hline Total & 4.66 & 0.57 & Highest \\
\hline
\end{tabular}

Table 3. The suitability evaluation result of the application of the suitability of the STEAMification model in flipped classroom learning environment $(n=17)$

\begin{tabular}{lccc}
\hline \multicolumn{1}{c}{ Evaluation Items } & Mean & S.D. & Suitability \\
\hline $\begin{array}{l}\text { The STEAMification } \\
\text { Model is suitable in } \\
\text { supporting learners' } \\
\text { creative thinking }\end{array}$ & 4.59 & 0.62 & Highest \\
\hline $\begin{array}{l}\text { The STEAMification } \\
\text { Model is suitable in } \\
\text { supporting learners to } \\
\text { develop creative } \\
\text { innovation }\end{array}$ & 4.53 & 0.72 & Highest \\
\hline $\begin{array}{l}\text { The STEAMification } \\
\text { Model is suitable in } \\
\text { usage possibility }\end{array}$ & 4.71 & 0.69 & Highest \\
\hline \multicolumn{1}{c}{ Total } & $\mathbf{4 . 6 1}$ & $\mathbf{0 . 6 7}$ & Highest \\
\hline
\end{tabular}

From Table 1-3 it is found that the STEAMification Model in flipped classroom learning environment has suitability score at the highest level (mean $=4.72, \mathrm{SD}=0.53$ ). When examining individual item we found that the Components of the STEAMification model in flipped classroom learning environment has suitability score at the highest level $($ Mean $=4.86$, S.D. $=0.35)$, the Processes of the STEAMification model in flipped classroom learning environment has suitability score at the highest level $($ Mean $=4.66$, S.D. $=0.55)$, and the application of the suitability of the STEAMification model in flipped classroom learning environment has suitability score at the highest level $($ Mean $=4.61$, S.D. $=0.67)$. 
7.2. The creative scores of students studying through the STEAMification model and the control group students studying through traditional approach

Table 4. The comparison of creative scores (total score 16)

\begin{tabular}{lccccc}
\hline Group & $\mathrm{N}$ & Mean & S.D. & $\mathrm{t}$ & Sig. \\
\hline $\begin{array}{l}\text { Control } \\
\text { Group }\end{array}$ & 30 & 12.90 & 1.56 & 5.13 & $.000^{*}$ \\
\hline $\begin{array}{l}\text { Experimental } \\
\text { Group }\end{array}$ & 30 & 14.53 & 0.77 & & \\
\hline$* \mathrm{P}<.05$ & & & & & \\
\end{tabular}

From Table 4 the comparison of creative scores of students studying through the STEAMification model (experimental group) and the control group students studying through traditional approach found that students who study through the STEAMification model has a higher creative score (Mean $=14.53$, S.D. $=0.77)$ than students who study through traditional approach $($ Mean $=12.90$, S.D. $=1.56)$.

\subsection{The quality score of the creative innovation of students who are studying through the STEAMification model and the control group students studying through traditional approach}

Table 5. The comparison of quality score of the creative innovation (Total score 16)

\begin{tabular}{lccccc}
\hline Group & $\mathrm{N}$ & Mean & S.D. & $\mathrm{t}$ & Sig. \\
\hline Control Group & 30 & 14.86 & 1.45 & 11.35 & $.000^{*}$ \\
\hline $\begin{array}{l}\text { Experimental } \\
\text { Group }\end{array}$ & 30 & 18.40 & 0.89 & & \\
\hline$* \mathrm{P}<.05$ & & & & & \\
\hline
\end{tabular}

From Table 5 it is found that the Comparison of the quality score of the creative innovation of students who are studying through the STEAMification model in flipped classroom learning environment (experimental group) and the control group students studying through traditional approach found that the students studying through the STEAMification model in flipped classroom learning environment has a higher quality score of creative innovation (mean $=18.40$, s.d. $=0.89$ ) than the students studying through traditional approach (Mean $=14.86$, S.D. $=1.45$ ).

\section{Discussion}

From the research, it was found that students studying through the STEAMification model in flipped classroom learning environment has higher creative thinking score than the students who are studying through traditional approach, and a higher score of quality of the creative innovation than the students studying through traditional approach, because the STEAMification process of 5 steps namely investigate, discovery, connect, create creative innovation, and reflect are learning process that encourages students to think creatively, participate in learning experiences as well as problem solving, collaboration and the use of creative thinking processes at work.

The research also demonstrated that creative thinking and creative innovation skills can be encouraged by using digital technologies such as virtual learning ecosystem, and gamification, and these can be applied via STEAMification education [3], [16].

The research result on the appropriateness of STEAMification model in flipped classroom learning environment on creative thinking and creative innovation found that it has a great potential to enhance undergraduate students' creative thinking and creative innovation skills, which align with the characteristics of the $21^{\text {st }}$ century skills as stated in the above mentioned research. It is therefore assumed that through the successful implementation of the developed model.

\section{Conclusions}

STEAMification, is a learning model that integrates a 5-step STEAM Education learning activity: investigating, discovery, connecting, creating, and reflecting, together with gamification elements, namely game mechanics, game dynamics, emotions. The learning activities are applied in a flipped classroom learning environment, which consists of a Face to Face Classroom and Online Learning. Technology that is used comprises Collaborative Cloud Learning including Publishing Cloud, Sharing Cloud, Meeting Cloud, Discussing Cloud, and Collaborating Cloud. This developed learning model can develop learners with creative thinking and creative innovation.

STEAMification model in a flipped classroom learning environment is a teaching method that allows learners to develop digital literacy and increase learning satisfaction, by using digital technology supported collaborative learning. The development of the model should increase the use of technology that can enhance the immersive learning experience. The use of immersive technologies such as Virtual Reality (VR), Augmented Reality (AR), Mixed Reality (MR), the use of Artificial Intelligence (AI) to analyze learning analytics will create an immersive learning environment. 


\section{Acknowledgements}

This research was supported by faculty of science and technology, Rajamangala University for Technology Suvarnabhumi and Department of Industrial Education, Faculty for Industrial Education and Technology, King Mongkut's Institute of Technology Ladkrabang, Thailand.

\section{References}

[1]. Voratitipong, A., Wannapiroon, P., \& Nilsook, P. (2019). Digital-Education Scenario for Thailand. International Journal of Innovation, Management and Technology, 10(2), 97-103.

[2]. Ongardwanich, N., Kanjanawasee, S., \& Tuipae, C. (2015). Development of 21 st century skill scales as perceived by students. Procedia-Social and Behavioral Sciences, 191(52), 737-741.

[3]. Conradty, C., \& Bogner, F. X. (2018). From STEM to STEAM: How to monitor creativity. Creativity Research Journal, 30(3), 233-240.

[4]. Baharin, N., Kamarudin, N., \& Manaf, U. K. A. (2018). Integrating STEM education approach in enhancing higher order thinking skills. International Journal of Academic Research in Business and Social Sciences, 8(7), 810-821.

[5]. Sojayapan, C., \& Khlaisang, J. (2020). The effect of a flipped classroom with online group investigation on students' team learning ability. Kasetsart Journal of Social Sciences, 41(1), 28-33.

[6]. Li, J., Zhang, X., \& Hu, Z. (2018). The design and application of flip classroom teaching based on computer technology. International Journal of Emerging Technologies in Learning (iJET), 13(10), 95-107.

[7]. Hakak, S., Noor, N. F. M., Ayub, M. N., Affal, H., Hussin, N., \& Imran, M. (2019). Cloud-assisted gamification for education and learning-Recent advances and challenges. Computers \& Electrical Engineering, 74, 22-34.
[8]. Leelitthum, C., Sintanakul, K., \& Nilsook, P. (2019). Conceptual Framework for the Development of a Professional Assessment System in Accordance with Professional Standards in the Business Computer Department. International Journal of E-Education, eBusiness, e-Management and e-Learning, 9(3), 220226.

[9]. Yaici, M., Oussayah, A., \& Takerrabet, M. A. (2018). Trust-based Context-aware Authentication System for Ubiquitous Systems. Procedia computer science, 134, 35-42.

[10]. Rahmawati, Y., Ridwan, A., \& Hadinugrahaningsih, T. (2019, January). Developing critical and creative thinking skills through STEAM integration in chemistry learning. In Journal of Physics: Conference Series (Vol. 1156, No. 1, p. 012033). IOP Publishing.

[11]. Perignat, E., \& Katz-Buonincontro, J. (2019). STEAM in practice and research: An integrative literature review. Thinking Skills and Creativity, 31, 31-43.

[12]. How, M. L., \& Hung, W. L. D. (2019). Educing AIThinking in Science, Technology, Engineering, Arts, and Mathematics (STEAM) Education. Education Sciences, 9(3), 184.

[13]. Koivisto, J., \& Hamari, J. (2019). The rise of motivational information systems: A review of gamification research. International Journal of Information Management, 45, 191-210.

[14]. Rodrigues, L. F., Oliveira, A., \& Rodrigues, H. (2019). Main gamification concepts: a systematic mapping study. Heliyon, 5(7), e01993.

[15]. Said-Metwaly, S., Kyndt, E., \& Van den Noortgate, W. (2020). The factor structure of the Verbal Torrance Test of Creative Thinking in an Arabic context: Classical test theory and multidimensional item response theory analyses. Thinking Skills and Creativity, 35, 100609.

[16]. Hursen, C., \& Bas, C. (2019). Use of gamification applications in Science Education. International Journal of Emerging Technologies in Learning (iJET), 14(01), 4-23. 